\title{
Richard Hooker e a Epístola de Tiago reconciliada com a justificação pela fé no século XVI
}

\author{
Richard Hooker and the Epistle of James \\ reconciled with justification by faith in the sixteenth century
}

Cesar Motta Rios*

\begin{abstract}
Resumo
A relação entre Tiago e a doutrina da justificação pela fé tem ocupado teólogos protestantes por séculos. Por meio de pesquisa bibliográfica em fontes primárias e secundárias, apresento Richard Hooker, importante teólogo da Igreja da Inglaterra no século XVI, e seu entendimento sobre o problema. Após uma apresentação do teólogo, justificada por se tratar de personagem praticamente não estudado em nosso contexto, exponho a doutrina da justificação pela fé conforme Hooker e sua conciliação com Tiago. Em seguida, demonstro que ele não está isolado em sua proposta, mas é antecedido por Melanchthon e Calvino, que, como ele, divergem de Lutero. Por fim, observo como sua proposta condiz com sua postura com relação a outras igrejas além dos limites da Inglaterra, e como seu exemplo pode ser proveitoso para o diálogo ecumênico hoje.
\end{abstract}

\section{Palavras-chave}

Anglicanismo. Reforma. Justificação. Tiago. Richard Hooker.

\begin{abstract}
The relationship between James and the doctrine of justification by faith has occupied Protestant theologians for centuries. Through bibliographic research on primary and secondary sources, I introduce Richard Hooker, an important theologian of the Church of England in the sixteenth century, and his understanding of the problem. Besides an introduction to the theologian, justified because he is a character practically not studied in our context, I expose the doctrine of justification by faith according to Hooker and its conciliation with James. Next, I demonstrate that he is not isolated in his proposal, but is preceded by Melanchthon and Calvin, who, like him, differ from Luther. Finally, I observe how his proposal is in accordance with his position regarding other churches beyond the boundaries of England, and how his example can be useful for ecumenical dialogue today.
\end{abstract}

\section{Keywords}

Anglicanism; Reformation; Justification; James; Richard Hooker.

[Texto recebido em abril de 2018 e aceito em julho de 2018, com base na avaliação cega por pares/ realizada por pareceristas ad hoc]

* Doutor em Literaturas Clássicas e Medievais. Pesquisador Independente. Integrante do Grupo de Pesquisa Bíblia, Arqueologia e Religião (EST). E-mail: cesarmottarios@gmail.com 


\section{Introdução}

A doutrina da justificação por graça mediante a fé é fundamental para os movimentos de Reforma do século XVI, sendo, inclusive, um ponto de convergência entre eles. ${ }^{1}$ Lutero e, em seguida, os reformadores em geral leriam Romanos 1.17 com grande tranquilidade. A mesma tranquilidade os acompanharia na leitura do capítulo 4 da mesma carta. Ver-se-iam, também, inseridos na primeira pessoa do plural de Rm 5.1: “Então, tendo sido justificados por fé $(\Delta ı \kappa \alpha \omega \theta \varepsilon \dot{v} \tau \varepsilon \varsigma$ oũv $\dot{\varepsilon} \kappa \pi i ́ \sigma \tau \varepsilon \omega \varsigma)$, temos paz junto a Deus por meio de nosso Senhor Jesus Cristo". Contudo, algumas testas franziriam diante de Tiago

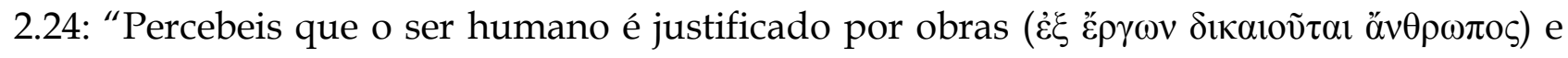

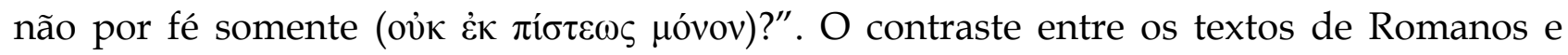
Tiago, no mínimo, exigia certo esforço intelectual.

É compreensível que teólogos católico-romanos tenham encontrado em Tiago um meio de refutar a doutrina da justificação como formulada por luteranos e reformados. ${ }^{2}$ Do lado protestante, haveria diferentes reações. Richard Hooker procurou demonstrar harmonia entre Tiago e a doutrina protestante. Este estudo apresenta sua argumentação. Antes, contudo, é oportuno dar notícia sobre quem é Hooker, por ser pouco conhecido no Brasil. Ademais, demonstro como se enquadra a proposta de Hooker em meio a três de seus antecessores. Por fim, nas considerações finais, refiro-me à relevância do teólogo.

\section{Richard Hooker}

No século XVII, Isaac Walton foi levado a escrever um longo texto sob o título $A$ vida do sr. Richard Hooker. Walton alega muita dificuldade por causa da distância no tempo. Hooker, com quem não havia convivido, morrera havia 64 anos! Em seguida, contudo, ele defende o valor de seu trabalho por ter tido contato próximo com pessoas que haviam convivido com Hooker, como William Cranmer, sobrinho-neto de Thomas Cranmer. ${ }^{3}$ A obra de Walton, embora apresentando uma narrativa um tanto romântica, é uma fonte importante sobre a vida do teólogo por sua proximidade cronológica, subestimada pelo autor. Recorro principalmente a ela nas linhas que seguem para esboçar uma exposição ordenada de elementos da vida de Richard Hooker.

Hooker nasceu em $1554,{ }^{4}$ na cidade de Exeter ou arredores. ${ }^{5}$ A Inglaterra passava por tempo de turbulência, sob o reinado de Maria I. A rainha, conhecida, não sem motivo,

1 PELIKAN, Jaroslav. The Christian Tradition: A History of the Development of Doctrine. v. 4: Reformation of Church and Dogma (1300-1700). Chicago: The University of Chicago Press, 1985. p. 138-139.

2 PELIKAN, 1985, p. 254-255.

3 WALTON, Isaac. The Life of Mr. Richard Hooker. In: The Works of Mr. Richard Hooker with a [...]. v. 1. London: J. F. Dove, 1825. p. 11.

4 Walton indica 1553 como ano de nascimento. Mais recentemente, o ano de 1554 tem sido mais aceito (EPPLEY, Daniel F. Richard Hooker (1554-1600). In: LINDBERG, Carter. The Reformation Theologians: An Introduction to Theology in the Early Modern Period. Oxford; Malden: Blackwell, 2002. p. 253). 
como "Maria sanguinária", desencadeou um processo de restauração do catolicismo romano no reino, que resultou no exílio de centenas de protestantes e execução de outros tantos em praça pública. ${ }^{6}$ Richard Hooker tinha, então, aproximadamente quatro anos de idade quando a Elisabeth I ascendeu ao trono. Em sua infância, no ano de 1559, viu ser promulgada nova Lei da Supremacia ${ }^{7}$ e a Lei da Uniformidade. ${ }^{8}$ Esta última lei, que definia a liturgia a ser utilizada e prescrevia a preservação das vestes e ornamentos tradicionais para todo culto, desagradou os exilados do período de Maria, que retornavam do continente com grande ímpeto polêmico contra tudo que se relacionava com a Igreja Romana. ${ }^{9}$ Esse posicionamento, que viria a ser conhecido como puritano, persistiria com força no âmbito da Igreja da Inglaterra, e seria enfrentado com vigor intelectual por Richard Hooker décadas mais tarde. Para chegar a tanto, o menino, filho de pais não abastados, precisaria estudar.

Sua carreira estudantil não ocorreu sem percalços, uma vez que seus pais não tinham condições financeiras para pagar por ela sem auxílio de um parente rico, John Hooker, tio de Richard. Mais tarde, John Hooker conseguiu que o bispo de Salisbury, John Jewel, também apadrinhasse o jovem estudante. Com o apoio decidido do Bispo, Richard ingressará no Corpus Christi College, Oxon. ${ }^{10}$

Quatro anos mais tarde, o bispo Jewel faleceria, deixando Richard Hooker, então com 18 anos de idade, apreensivo sobre a continuidade nos estudos. Mas não haveria retrocesso. Novo apadrinhamento surgiria e, logo, Hooker seria colocado na função de tutor de filhos de famílias importantes. Os estudos prosseguiram e, em 1577, Hooker foi escolhido como fellow na Universidade de Oxford. ${ }^{11}$ Em seguida, seria ordenado como diácono e sacerdote. ${ }^{12}$

Em 1584, Hooker se casa e vive um tempo difícil, como pastor em Draiton, Buckinghanshire. Seus dois pupilos destacados, Edwin Sandys e George Cranmer o visitam e reconhecem sua situação penosa. ${ }^{13}$ Sandys recorre a seu pai, então bispo de

5 Enquanto Walton (1825, p. 13) formula assim a localização, Joseph Lecler (LECLER, Joseph. Toleration and the Reformation. v. 2. Translated by T. L. Westow. New York: Association Press; London: Longmans, 1960. p. 398) define a localidade do nascimento como sendo Heavitree, que, no século XVI, estava nos arredores de Exeter, cidade que cresceria e abarcaria Heavitree como subúrbio.

6 WALKER, W. et al. História da Igreja Cristã. São Paulo: ASTE, 2008. p. 578-579.

7 Lei que excluía da Inglaterra qualquer autoridade papal. A primeira havia sido invalidada no período da Rainha Maria.

8 WALKER, 2006, p. 581-582.

9 WALKER, 2006, p. 582.

10 WALTON, 1825, p. $14-15$.

11 WALTON, 1825, p. 20.

12 WALTON, 1825, p. 22.

13 WALTON, 1825, p. 23-24. Issac Walton narra essa situação, com traços dramáticos, como causada por um casamento infeliz e falta de recursos. 
Londres, que oferece a Hooker o posto de Master of the Temple. ${ }^{14}$ Aos 34 anos de idade, em março de 1585, Richard Hooker assume a função e muda-se para Londres. ${ }^{15}$

Não seria, contudo, um trabalho tranquilo. Quando assume o posto de Master of the Temple, Hooker se insere em uma controvérsia que estava em andamento. Certo Walter Travers, que estava envolvido em uma tentativa frustrada de alcançar o posto de Master of the Temple, seria um rival ferrenho de Hooker. ${ }^{16}$ Travers era um importante representante dos que não se conformavam com a Lei da Unidade. Mesmo tendo obtido posto de pregador na Temple Church, recusava-se a receber a ordenação, considerando válida para a Inglaterra uma ordenação presbiteriana que recebera na Antuérpia e tendo por biblicamente errôneos os ritos previstos pelo Livro de Oração Comum..$^{17}$ Segundo Walton, seu objetivo era estabelecer um governo presbiteriano na Temple Church. ${ }^{18}$ Sua pregação era de tal forma alinhada com a teologia e a práxis de grupos reformados do continente, que a situação dos sermões abertamente conflitantes podia ser bem descrita assim: "Nos sermões matutinos [proferidos por Hooker], fala a Cantuária. Nos da tarde [proferidos por Travers], Genebra". 19

Esse confronto vivenciado cotidianamente com a proposta puritana antecederia o enfrentamento livresco que seria possibilitado após 1591, quando, retirando-se da função na Temple Church, Richard Hooker passaria a escrever sua grande obra: Das Leis da Política Eclesiástica. ${ }^{20}$ Jaroslav Pelikan reconhece nesse escrito "um dos mais ambiciosos esforços apologéticos dentro do protestantismo" daquele tempo. ${ }^{21}$ Hooker defende a organização política e litúrgica da Igreja da Inglaterra conforme o estabelecido pela rainha Elizabeth I, argumentando longamente contra o que ele considera exagero dos puritanos. Sua dedicação revela uma percepção bastante realista do risco que representava para a Igreja da Inglaterra o desenvolvimento das ideias e o fortalecimento dos grupos puritanos. Décadas mais tarde, a revolução de Oliver Cromwell demonstraria que o esforço de Hooker não era desproporcional. ${ }^{22}$

\footnotetext{
Temple Church, no centro de Londres.

WALTON, 1825, p. 26.

WALTON, 1825, p. 30.

7 GUGLIERMETTO, Gianluigi. Il pensiero di Richard Hooker all'origine della teologia anglicana. Protestantesimo, v. 69, 2014. p. 354-355.

18 WALTON, 1825, p. 45.

19 WALTON, 1825, p. 46.

20 A última década da vida de Hooker é dedicada à escrita. A partir de 1595, ele vivia em uma casa pastoral que ficava a três milhas da Cantuária. Muitos acadêmicos iam até sua residência para conhecer o famoso teólogo. Encontravam não um homem altivo, mas uma pessoa humilde em roupas simples (WALTON, 1825, p. 64). Ele trabalhava de modo dedicado e sereno como pastor da igreja local (WALTON, 1825, p. 67-69). Caiu enfermo, e faleceu aos 46 anos após uma vida exemplar de moderação (WALTON, 1825, p. 70).

21 PELIKAN, 1985, p. 348. Trata-se de um conjunto de 5 livros, acrescidos de mais 3 publicados postumamente. Destes últimos, dois têm a autenticidade da autoria questionada (LECLER, 1960, p. 398.).

22 GUGLIERMETTO, 2014, p. 354.
} 
Um ponto central da argumentação de Hooker diz respeito ao uso da Bíblia nas querelas impostas pelos puritanos. A ideia de que as doutrinas verdadeiras deveriam ser encontradas nas Escrituras já havia sido entoada na Inglaterra, a partir de Oxford, por obra de John Wycllife, inclusive. Portanto, a infiltração do princípio do Sola Scriptura em terras inglesas por meio dos escritos de Lutero, por volta dos anos 1520, encontrou um precursor importante. ${ }^{23}$

Hooker acolhe o princípio. ${ }^{24}$ Reconhece a suficiência da Escritura para o propósito a ela atribuído por Deus, a salvação dos seres humanos, mas alerta para o erro de nelas se buscarem orientações inexistentes. O que ali não está definido, como detalhes sobre a organização eclesiástica, deve ser buscado não em simples leitura da Bíblia, mas por entendimento racional. ${ }^{25}$ Hooker assinala o erro de seus opositores:

\begin{abstract}
Supões que as Leis, pelas quais lutas, encontram-se nas Escrituras, mas que aquelas, pelas quais nós lutamos, não. E, a partir dessa conjectura, és levado a sustentar, como o principal pilar de tua causa inteira, que "A Escritura deve ser a única regra de todas as nossas ações". Consequente, as ordens eclesiásticas que nós observamos, não sendo ordenadas na Escritura, são ofensivas e desagradáveis a Deus. ${ }^{26}$
\end{abstract}

A partir desse entendimento, a defesa da Lei da Unidade não precisava tornar-se uma busca por textos-prova no Antigo ou no Novo Testamento. Estava admitido que não partiam das Escrituras todas as estruturas eclesiásticas existentes. Ainda assim, seu trabalho não é meramente o de um jurista ou cientista político. A questão teológica está inserida decididamente. Parte de seu propósito era demonstrar que “o culto na Igreja elisabetana era um efetivo meio para salvação".${ }^{27}$ Afinal, se os detratores propunham que a Igreja ainda não havia sido purgada de todo paganismo trazido pelo romanismo, ${ }^{28}$ era preciso demonstrar que o que se tinha estabelecido, desde o governo da Igreja até sua liturgia, era benéfico e não perturbador da função própria da Igreja.

Saliento que Richard Hooker não propõe que toda a cristandade do mundo siga o modelo da Igreja da Inglaterra. O empenho apologético de Hooker não é destinado ao convencimento de outros corpos eclesiais, mas visa a manutenção do que havia sido estabelecido naquele âmbito específico. A catolicidade da Igreja não depende de sua

\footnotetext{
3 GUGLIERMETTO, 2014, p. 355-356.

EPPLEY, 2002, p. 261.

PELIKAN, 1985, p. 348-349.

26 HOOKER, Richard. A Preface To Them That Seek (As They Term It) The Reformation [...] In: The Works of Mr. Richard Hooker with a [...]. V. 1. London: J. F. Dove, 1825. p. 130.

27 EPPLEY, 2002, p. 253.

28 Os opositores afirmavam que as ordens da Igreja "corromperam a forma correta da política eclesial, com vários ritos e cerimônias papistas, que certas Igrejas reformadas baniram de seu meio, e que elas deram, portanto, a nós tal exemplo que (assim pensas) precisamos seguir" (HOOKER, 1825, p. 130).
} 
política, aspectos exteriores ou unidade institucional. ${ }^{29}$ A porta de entrada para a Igreja visível é uma somente: o Batismo. ${ }^{30}$

Essa perspectiva de Hooker faz com que tenha um entendimento diverso do de muitos protestantes do século XVI a respeito da Igreja Romana. As Igrejas oriundas das reformas não são uma nova Igreja, mas a mesma de sempre:

[...] eles nos perguntam onde nossa Igreja ficou escondida, em que caverna da terra ela dormiu, por tantas centenas de anos, antes do nascimento de Martim Lutero? Como se fosse nossa opinião que Lutero erigiu uma nova Igreja de Cristo. Não, a Igreja de Cristo, que era desde o princípio, é e continua até o fim. De tal Igreja, as partes todas não têm sido sempre igualmente sinceras e boas. ${ }^{31}$

Para ser Igreja Visível de Cristo sobre a Terra não é preciso perfeição absoluta, de prática ou doutrina. Até mesmo a afirmação da necessidade de obras para a salvação não deveria ser vista necessariamente como uma ruptura absoluta com o fundamento da fé cristã, como defende Hooker em seu Um Discurso Erudito sobre a Justificação. Para o teólogo, o que a Igreja Romana acrescentava como necessário para a salvação era de natureza diversa do que os gálatas reprovados por Paulo acrescentavam, uma vez que estes substituíam/excluíam a pertinência de Cristo com a imposição circuncisão como meio de entrada no povo de Deus, enquanto a Igreja Romana fazia mais elementos dependentes de Cristo serem agregados como necessários. Cristo, neste último caso, permanece como fonte da salvação. 32

Hooker é um notável intelectual cristão comprometido com as confissões da Igreja da Inglaterra, ao mesmo tempo em que enfatiza o caráter especialíssimo das Escrituras, requisitando, é certo, cuidados hermenêuticos por parte da comunidade leitora.

\section{A justificação pela fé e Tiago em Hooker}

O entendimento de Hooker a respeito da Epístola de Tiago e sua conciliação com a doutrina da justificação por fé aparece em seu Um Discurso Erudito sobre a justificação, de meados da década de 1580. Para entender a proposta, é preciso, antes, considerar o que o

29 "A Igreja Católica está, de certa forma, dividida em certo número de diferentes sociedades, cada uma das quais é chamada Igreja dentro dela mesma" (HOOKER, 1825, p. 279).

30 HOOKER, 1825, p. 272. O comportamento, por exemplo, não é tido por Hooker como marca de pertencimento à Igreja visível, embora possa privar a pessoa da salvação. A partir da noção de "homem cristão", ele observa que honestidade e justiça moral constituem o que é próprio do homem, mas que a marca do cristão é simplesmente "um Senhor, uma fé, um batismo".

31 HOOKER, 1825, p. 275.

32 HOOKER, Richard. A Learned Discourse of Justification, Works, and how the Foundation of Faith is Overthrown. In: The Works of Mr. Richard Hooker. Arranged by The Rev. John Keble. v. 3. Oxford: Clarendon Press, 1884. p. 529. 
teólogo entende a respeito da justificação em si. Felizmente, ele expõe a doutrina da justificação de modo muito claro e sistemático. O seguinte trecho é significativo:

Há uma justiça do homem da glória no mundo por vir; e há uma justiça da justificação e uma da santificação aqui. A justiça com a qual haveremos de ser vestidos no mundo por vir é tanto perfeita quanto inerente. Aquela por meio da qual nós somos justificados é perfeita, mas não inerente. Aquela por meio da qual somos santificados, inerente, mas não perfeita. ${ }^{33}$

Há uma ênfase na justiça relativa à santificação, inclusive pela indicação clara de que se trata de algo realizado no ser humano, ao contrário da justiça da justificação, que é declarativa/forense. Ele tem o cuidado de não fazer a segunda depender da terceira. Isto é, as obras da justiça da santificação não são causa da justiça da justificação, mas fruto da mesma dinâmica viabilizada pela justiça de Cristo e obra do Espírito Santo. ${ }^{34}$ Aquele que é justificado o é por ação de Deus, que não é movido por mérito algum do ser humano, mas que, por decisão própria, predestinou certo número de pessoas para a salvação. ${ }^{35} \mathrm{E}$, para salvação desses, usa ordinariamente os meios da graça, Palavra e sacramentos. ${ }^{36}$

Hooker procura expor uma doutrina da justificação por fé somente que preserve claramente a pertinência das obras e da Igreja. Nesse contexto, aborda a Epístola de Tiago, não estando disposto a discutir o cânone neotestamentário: "Pois se não há ambiguidade em algum termo, São Paulo e São Tiago se contradizem; o que não pode acontecer". 37 Seu pressuposto está estabelecido: Tiago é Escritura Sagrada. Isso, inclusive, porque ele está comprometido com os 39 Artigos de Religião de 1571. No sexto artigo, lê-se: “Todos os Livros do Novo Testamento, como eles são comumente recebidos, nós os recebemos sim, e os temos por Canônicos".

Em seguida, o teólogo afirma que a ambiguidade não está no uso dos termos "fé" e "obras". Paulo e Tiago os utilizam com o mesmo sentido. A diferença se explicaria pelo simples fato de que, ao tratar de justificação, Paulo não traria implicitamente o assunto da santificação, enquanto Tiago sim. ${ }^{38}$ Recupera, então, o tema das duas justiças, a primeira imputada e externa tem a companhia da segunda, aquela em nós, que consiste nas virtudes cristãs. Ao usar o versículo de Gênesis 15.6 como prova em seu texto, o autor da epístola estaria tratando das duas justiças de modo bem ordenado: ele mostraria a justiça inerente,

33 HOOKER, 1884, p. 485.

34 Cf. EPPLEY, 2002, p. 254. Há certa semelhança com o desenvolvido por Lutero sobre as duas justiças. Gibbs observa que a contribuição de Hooker para a doutrina da justificação não se fundamentaria em alguma novidade proposta, mas no cuidado de apresentar o assunto com detalhes e identificar respeitosamente os pontos de contraste entre Católicos e Protestantes (GIBBS, Lee W. Richard Hooker's Via Media Doctrine of Justification. Harvard Theological Review, v. 74, n. 2, abr. 1981. p. 220).

35 Cf. EPPLEY, 2002, p. 255.

36 Cf. EPPLEY, 2002, p. 256.

37 HOOKER, 1884, p. 506. Grifo meu.

38 HOOKER, 1884, p. 507. 
a segunda, que se manifesta em obras, e, em seguida, a primeira, que é imputada pela fé, e está como causa eficiente para a segunda. ${ }^{39}$

Hooker tem o cuidado de distinguir, ainda, dois tipos de justiça da santificação, inerente, de modo a deixar claro como a obra de Abraão é efeito e não causa. Há a justiça santificadora habitual e a atual. A santidade habitual nos é dada no mesmo instante em que passamos a ser habitação do Espírito Santo. A outra, atual, é relacionada aos atos, às ações, que, a partir da santidade habitual, realizam-se na vida dos cristãos. ${ }^{40}$

A justificação em sentido forense, imputada e não inerente, é a principal em dignidade, mas em uma ordem natural (não temporal) segue à justiça da santificação habitual. A justiça da santificação habitual, realizada pela presença do Espírito, é imprescindível para haver fé, meio da justificação em sentido forense. Mas esse ensino preserva a justificação livre do mérito de qualquer obra. A justiça da santidade atual, das obras resultantes, segue à justiça imputada e à justiça da santificação habitual, vindo depois delas, tanto na ordem quanto no tempo. ${ }^{41}$

Conforme Hooker, quando se considera atentamente essa relação entre as duas justiças e, em seguida, entre as duas justiças relativas à santidade:

[m]ostra-se claramente como a fé dos verdadeiros crentes não pode ser dissociada da esperança e do amor; como a fé é uma parte da santificação, e, ainda assim, necessária para a justificação; como a fé é aperfeiçoada por boas obras, e, ainda assim, nenhuma obra nossa é boa sem fé; finalmente, como nossos pais podiam sustentar que 'Nós somos justificados por fé somente', e, ainda assim, sustentar verdadeiramente que, sem boas obras, nós não somos justificados. ${ }^{42}$

A completude da fé se dá com a companhia do amor e da esperança, que resulta em obras. Nesse sentido, a fé é aperfeiçoada por boas obras. Sem ser explícito em seu movimento exegético, Hooker acolhe em seu discurso a proposição de Tiago 2.22.

Em seguida, o teólogo observa que os pais não tinham em mente propriamente um merecimento de recompensa por causa dessas boas obras. Até mesmo usando o verbo "merecer", pensavam em "obter". É significativo que, como exemplo, cite o trecho de uma confissão produzida por luteranos:

Os antigos pais usam merecer por obter, e é nesse sentido que os de Wittenberg têm em sua Confissão: 'Nós ensinamos que boas obras

\footnotetext{
39 HOOKER, 1884, p. 507.

40 HOOKER, 1884, p. 507.

41 HOOKER, 1884, p. 508; Cf. GIBBS, 1981, p. 220.

42 HOOKER, 1884, p. 508.
} 
ordenadas por Deus devem necessariamente ser feitas, e que, por livre bondade de Deus, elas merecem certas recompensas'. ${ }^{43}$

O trecho lhe serve bem, uma vez que a expressão "por livre bondade de Deus" indica claramente que o "merecem" não tem o pleno sentido do verbo "merecer" em seu uso cotidiano. A escolha de Hooker ainda é significativa por outros motivos: 1) De alguma forma, explicita a atenção do teólogo para as discussões que se haviam desenrolado no Concílio de Trento, algo implícito em sua discussão; 2) Demonstra que sua proposta de inserção das boas obras de modo claro na exposição de sua doutrina não é inovação mesmo com relação aos luteranos; 3) Sugere que, se Lutero não entendeu a pertinência de Tiago, o mesmo não deveria necessariamente acontecer com os luteranos subsequentes.

Hooker procura defesa para uma acusação que se dirigira e se dirigia também aos luteranos na Alemanha. Não é inusitado, pois, constatar alguma semelhança em suas reações. O teólogo inglês assevera:

É uma picuinha infantil com que, no assunto da justificação, nossos adversários se comprazam tão grandemente, exclamando que nós pisoteamos todas as virtudes cristãs sob nossos pés, e não requeremos nada nos cristãos a não ser fé, porque ensinamos que a fé somente justifica; na verdade, com esse discurso, nós nunca pretendemos excluir nem a esperança nem o amor de estarem sempre unidos como companheiros inseparáveis da fé no homem que é justificado. ${ }^{4}$

Poucos anos antes, os luteranos afirmavam:

Depois que o homem foi justificado pela fé, uma fé verdadeira e viva "atua pelo amor", Gl 5. Assim, que as boas obras sempre seguem à fé justificante e, se é verdadeira e viva, certamente são encontradas com ela, visto que nunca está só, porém sempre vem acompanhada de amor e esperança. 45

Não é despropositado pensar que o uso (repetido) do adjetivo "viva" para caracterizar a fé seja um reflexo da leitura de Tiago, ou mesmo uma demonstração de que a doutrina proposta não é negada pelo que se lê naquela epístola.

A seguir, observarei como a proposta de Hooker a respeito de Tiago se encontra em meio a importantes reformadores do século XVI.

43 HOOKER, 1884, p. 508. Não se trata da Confissão de Augsburgo, mas de documento apresentado pelos embaixadores do Duque de Württemberg no Concílio de Trento em 1552.

44 HOOKER, 1884, p. 540.

45 Fórmula de Concórdia, Epítome III, 8. Esse texto foi composto entre 1576 e 1577 (cf. GASSMANN, Günther. As confissões luteranas - Os textos. In: HENDRIX, Scott; GASSMANN, Günther. As Confissões Luteranas: Introdução. São Leopoldo: EST / Sinodal, 2002. p. 47-48). Acusações semelhantes haviam sido levantadas décadas antes (cf. CA XX). 


\section{O posicionamento de Hooker em vista de Lutero, Melanchthon e Calvino}

É inevitável lembrar de Lutero e sua repulsa declarada à Epístola de Tiago. Robert Kolb procura demonstrar que a famosa atribuição do título "Epístola de palha" 46 a Tiago por parte do reformador não deveria ser tida como indício de uma reprovação absoluta. Afirma que Lutero foi assim depreciativo somente quando se tratava de discutir a utilidade da carta para a proclamação de Jesus e da salvação. Observa que a carta de Tiago era usada por Lutero para ensinar um comportamento piedoso, e atribui a perpetuação da fama da repulsa a anotações de alunos do reformador. ${ }^{47}$

De fato, Lutero concedia algum valor ao escrito, de modo que podia citar Tiago até mesmo em seu Catecismo Maior. ${ }^{48}$ Não obstante, parece-me que Kolb deixa de considerar afirmações relevantes de Lutero. Mesmo na última versão do prefácio para a epístola em sua tradução da Bíblia, o reformador mostra clara insatisfação, embora reconheça algo de proveitoso no texto, e afirme tratar-se de um livro bom e louvável. ${ }^{49}$ Ele propõe o reconhecimento de uma diferença de estatuto entre Tiago e outros livros bíblicos. Considere-se o seguinte parágrafo:

Em primeiro lugar, ela [a Epístola de Tiago] está completamente contra São Paulo e todo o resto das Escrituras ao atribuir a justificação a obras [2.24]. Diz que Abraão foi justificado por suas obras quando ofereceu seu filho Isaque [2.21]; embora, em Romanos 4[2-22], São Paulo ensine o contrário, que Abraão foi justificado a parte de obras, por sua fé somente, antes que tivesse oferecido seu filho, e o prova por Moisés em Gênesis 15[.6]. Agora, embora essa epístola possa ser socorrida e uma interpretação possa ser concebida para essa justificação por obras, não pode ser defendida na sua aplicação a obras [Tg 2.23] da afirmação de Moisés em Gênesis 15[.6]. Pois Moisés está falando aqui somente da fé de Abraão, e não de suas obras, como são Paulo demonstra em Romanos 4. Esse erro, portanto, prova que essa epístola não é obra de nenhum apóstolo. ${ }^{50}$

Lutero encontra um problema cronológico que lhe parece irresolvível. Tiago afirma a justificação como relacionada com o sacrifício de Isaque, que só acontece bem depois de, no capítulo 15, o texto de Gênesis afirmar que Abraão havia sido justificado. Kolb não se refere a esse argumento. Por isso, deixa de enfrentar o fato de que Lutero, mesmo conhecendo tentativas de conciliação, persiste em afirmar uma imperfeição na epístola, e uma inadequação com respeito a outras partes do cânone. Isso é reforçado no argumento seguinte: A epístola se refere a Cristo, mas nada ensina a respeito dele, enquanto "todos os livros sagrados genuínos concordam nisto: todos eles pregam e

46 LW, v. XXXV, p. 362.

47 KOLB, Robert. Martin Luther and the Enduring Word of God: The Wittenberg School and Its ScriptureCentered Proclamation. Grand Rapids: Baker Academic, 2016. p. 93.

48 Cf. CM, $3^{\text {a }}$ parte, última petição, 123.

49 LW, v. XXXV, p. 395.

50 LW, v. XXXV, p. 396. 
inculcam Cristo". ${ }^{51}$ Parece-me que é justamente por colocar a Epístola de Tiago à parte dos livros sagrados genuínos que Lutero pode afirmar adiante que o autor "queria prevenir contra aqueles que confiam na fé sem obras, mas era inapto para a tarefa". ${ }^{52}$ Uma afirmação assim não chamaria a atenção se produzida em muitos contextos teológicos da atualidade, mas se destaca vindo de Lutero, que, sobre uma peculiaridade vocabular presente em diferentes livros canônicos podia afirmar: "Mas eu estou inclinado a concordar com aqueles que declaram que 'irmãos' realmente significa 'primos' aqui, pois $o$ Espírito Santo e os judeus sempre chamam primos de irmãos". 53 A autoria final de diversos livros da Bíblia pode ser atribuída ao Espírito Santo, mas isso parece não valer para a Epístola de Tiago, cujo autor pode ser acusado de inépcia.

Lutero não se impõe a todos os luteranos, uma vez que, já na Apologia da Confissão de Augsburgo (1530-1531), Filipe Melanchthon providenciava uma interpretação que mostrava a justificação pela fé não sendo rivalizada pelo texto de Tiago. 54 Martim Lutero reconhece que a epístola poderia ser "socorrida" em certo sentido, mas afirmava não ser o suficiente. Possivelmente, contava entre esses socorros a interpretação apresentada pelo amigo Melanchthon, que observa que, diferente de seus opositores romanos, Tiago não ocultava a fé ao falar das obras, mas fazia as obras figurarem junto com a fé (Apol. IV, 245). Para o reformador humanista, Tiago pressupõe a fé como fonte das obras, o que se evidenciaria em sua discussão sobre "fé viva" e "fé morta". A obra é evidência da fé viva por ser produto dela (Apol. IV, 246). Em seguida, recorrendo a versículo anterior à discussão sobre obras e fé, Melanchthon encontra em Tg 1.18 a prova de que Tiago também afirma a regeneração pelo Evangelho. Essa afirmação deveria ser a base para a leitura da discussão seguinte (Apol. IV, 247). Quanto à frase problemática de Tg 2.24, afirma: "Nem descreve, aqui, o modo da justificação; descreve como são os justos, depois de já justificados e renascidos" (Apol. IV, 252). Acrescenta que o caso de Tiago seria como de Rm 2.13: “Os que praticam a lei hão de ser justificados”. Essas palavras não indicam que a justificação se deva à prática, mas que:

São pronunciados justos os homens que têm fé e boas obras. Sim, pois as obras dos santos, como dissemos, são justiças e agradam em razão da fé. Pois Tiago inculca apenas as obras produzidas pela fé, conforme atesta ao dizer de Abraão: "A fé opera juntamente com as suas obras". 55

Em Genebra, encontraremos também Calvino lidando com o assunto. O reformador francês se refere às dúvidas com relação a Tiago para manifestar discordância:

\footnotetext{
$51 \quad$ LW, v. XXXV, p. 396.

52 LW, v. XXXV, p. 397.

53 LW, v. XXII, p. 215.

54 Karlstadt já havia se oposto a Lutero nesse assunto anos antes, no início da década de 1520.

55 Apol. IV, 252.
} 
E, ainda hoje, há alguns que não consideram que ela [a Epístola de Tiago] deva ser tida por Escritura autêntica. Não obstante, de minha parte, porque não vejo motivo que seja suficiente para rejeitá-la, eu a recebo de bom grado, e sem opor-lhe dificuldade alguma. Pois, quanto, ao que parece, à opinião de que o segundo capítulo inverte a doutrina da justificação gratuita, nós resolveremos facilmente essa dúvida, quando chegar a exposição da passagem. E quanto àquilo que se poderia pensar que não magnifica a graça de Cristo da forma como deve fazer um apóstolo, certamente, a resposta é fácil, a saber que nós não devemos requerer precisamente que todos tratem de um mesmo argumento ou ponto da doutrina. Há o que se dizer dos livros de Salomão junto ao estilo de Davi. Pois enquanto Salomão se dedica mais a formar e moldar o homem exterior, e a tratar das regras e preceitos concernentes à vida política, se sabe bem que Davi versa constantemente sobre o serviço espiritual de Deus, o repouso da consciência, a misericórdia de Deus, e a promessa gratuita de salvação, e quase não fala de outra coisa. Contudo, essa diversidade não faz com que, aprovando um, condenemos o outro. ${ }^{56}$

É bem perceptível que, além de não compartilhar das dúvidas com respeito a Tiago, opõe-se claramente aos mesmos argumentos levantados por Lutero anos antes.

No corpo do comentário, Calvino ressalta o versículo 20, que afirma ser morta a fé sem obras como sinal de que o que se discute no trecho ao se falar de fé não é a causa da justificação, mas o fato de que não se deve pensar que essa fé deva vir desacompanhada de obras. Em seguida, o reformador toma um cuidado perceptível para, defendendo Tiago, não introduzir as obras como causa, ainda que parcial, da justificação. A estratégia reside em afirmar a polissemia do termo justificação, que, em Paulo, indicaria a imputação gratuita da justiça "diante do tribunal de Deus", enquanto, em Tiago, tratar-se-ia de "uma declaração ou aprovação de justiça pelas obras ou efeitos, e isto diante dos homens". ${ }^{57}$ Paulo trata da fonte da justificação. Tiago, dos efeitos dessa justificação, daquilo que a torna evidente diante das pessoas.

Esse princípio rege o que se segue na interpretação. Assim, quando diz que a fé é aperfeiçoada pelas obras, Tiago não estaria propondo que a fé toma sua perfeição das obras, mas que, pelas obras, ela é comprovada como sendo verdadeira diante das pessoas, como existente. A frase nada teria a ver com a situação real do ser humano diante de Deus. $^{58}$

Em seguida, Calvino trata da citação de Gênesis 15, que Lutero acusa de errônea. Segundo o reformador de Genebra, haveria mesmo erro de Tiago caso estivessem certos os que afirmam que ele propõe uma justificação cuja fonte fossem as obras. Contudo, o cumprimento mencionado a propósito versículo da Torah citado não seria a justificação

56 CALVINO, João. Épistre Catholique de S. Jaques. In: Commentaires de Jean Calvin sur le Nouveau Testament. Tome Quatriême. Paris: Librairie de Ch. Meyrueis et Compagnie, 1855. p. 694.

57 CALVINO, 1855, p. 716.

58 CALVINO, 1855, p. 717. 
por obras, mas o fato de que a fé em questão não era ociosa. Novamente, o assunto seria a consequência da justificação, acontecida antes. ${ }^{59}$

Calvino, então, propõe que o versículo 24, que parece estar literalmente em oposição a Paulo, seja lido como bem atrelado ao que antes se desenvolveu, de modo que assim se entenda: “O homem não é justificado somente pela fé, isto é, por um conhecimento de Deus nulo e vão. Ele é justificado por obras, isto é, sua justiça é conhecida e aprovada pelos frutos". 60

Convém observar que Calvino não remete a $\mathrm{Tg}$ 1.18, como Melanchthon, ao discutir o segundo capítulo da epístola. Não obstante, lembre-se de que o que ele escreve é um comentário de toda a carta. Ele entende que seu leitor já foi comunicado sobre Tiago afirmar a justificação por fé, e que:

a passagem [Tg 1.18] nos ensina que como nossa eleição antes da criação do mundo é gratuita, assim também, pela pura graça de Deus nós somos iluminados no reconhecimento da verdade: de modo que a vocação responde à eleição. ${ }^{61}$

Tendo considerado esses três teólogos emblemáticos, torna-se claro que o posicionamento de Richard Hooker se alinha com Melanchthon e Calvino, ainda que com diferenças, e se opõe à postura de Lutero. Muito facilmente, observa-se que, enquanto Lutero encontrava na contradição um motivo para dissociar Tiago das Escrituras, Hooker encontra na unidade das Escrituras um motivo para negar a possibilidade da contradição. E o faz, diferente de Calvino, sem sequer mencionar a possibilidade de diferença no estatuto canônico de Tiago. Outra diferença com relação a Calvino reside no fato de que Hooker não recorre ao entendimento da justificação em Tiago como relacionada a um reconhecimento de justiça diante das pessoas (e não diante de Deus), embora ambos explorem, ainda que diferentemente, uma diferença semântica no uso de "justificação" por Paulo e Tiago. Para Hooker, a diferença reside no que está implicado no termo (só o ato forense ou todos os desdobramentos). Para Calvino, a diferença está na perspectiva (Deus ou outros humanos). Hooker se detém na demonstração de que Tiago não afirma serem as obras a causa da justificação, mas seu efeito. O que o escritor neotestamentário faz seria demonstrar enfaticamente que a fé verdadeira é necessariamente acompanhada de obras. O objetivo de Hooker é o mesmo de Melanchthon. Uma diferença entre os dois está no fato de que, enquanto o inglês fortalece sua argumentação por meio de uma correlação entre o texto de Tiago e sua complexa sistematização teológica, o reformador germânico se dedica a uma abordagem mais textual. Ambos, deve-se notar, afirmam em trechos aqui citados

59 CALVINO, 1855, p. 717.

60 CALVINO, 1855, p. 717.

61 CALVINO, 1855, p. 703. 
que as boas obras só agradam a Deus em razão da fé, o que faz desta o pressuposto para aquelas.

Talvez, afastar-se de Lutero, no presente caso, fosse necessário para favorecer o diálogo. Melanchthon, mais conciliador que seu colega, 62 já o fizera antes. Hooker, que estabelece uma abertura significativa para o diálogo e a convivência com Roma, provavelmente, também o faria mesmo que não estivesse já incumbido disso pelos 39 Artigos de Religião.

Algo curioso e importante de se acrescentar é que Hooker convidaria os leitores a não se assustarem com a diversidade de opiniões aqui discernida. Na conclusão de $U m$ Discurso Erudito sobre a Justificação pela Fé, o teólogo recorre a Tiago 2.1, que condena a acepção de pessoas associada à fé em Jesus Cristo, para introduzir uma exortação à parcimônia diante da diversidade de opiniões teológicas:

Vocês já devem ter aprendido que não é em si mesmo danoso, nem deve ser para ninguém escandaloso e ofensivo, que, em casos permeados por dúvidas, se escutem entendimentos diferentes da parte dos homens. Seja o caso de Cefas ter uma interpretação e Apolo outra; que Paulo tenha seu pensamento, e Barnabé outro. Se isso os ofende, o erro é de vocês. Tenham mentes pacíficas, de modo que possam ter conforto nessa diversidade. ${ }^{63}$

\section{Considerações finais}

Tanto a vida e a obra de Hooker em geral quanto sua proposta a respeito da justificação pela fé e Tiago me sugerem ser ele personagem relevante quando se quer ou se precisa pensar sobre caminhos de diálogo entre diferentes tradições cristãs. Em um contexto tenso e complexo, ele procurou ser ponderado e respeitoso para com as diferenças, ainda que, no que diz respeito à Inglaterra, fosse intransigente com a investida daqueles que, a seu ver, negariam o direito da Igreja da Inglaterra persistir com suas características próprias. É, portanto, um exemplo de alguém com respeito e zelo por sua tradição, sem que, para tanto, tivesse que recorrer ao desmoronamento das demais.

No trato da justificação pela fé e da Epístola de Tiago, Richard Hooker mantém a afirmação do Cânone em sua inteireza, o que seria importante para que o ponto de convergência entre as diferentes igrejas se mantivesse. Ao mesmo tempo, sem negar justificação pela fé, encontra lugar importante para as obras (e para Tiago), algo também proveitoso para que se mantenha clara conexão com a tradição da Igreja ao longo dos séculos, e se possa dialogar equilibradamente com tradições que não passaram ou não se submeteram às reformas do século XVI.

62 Confira a proposta de Lutero sobre a condição de sujeição de pastores aos bispos romanos (AE X) e a de Melanchthon (Apol. XIV, 5). O mesmo com respeito à "missa" na CA (XX, 2-3) e em Lutero (AE II).

63 HOOKER, 1884, p. 547. 


\section{Referências}

CALVINO, João. Épistre Catholique de S. Jaques. In: Commentaires de Jean Calvin sur le Nouveau Testament. Tome Quatriême. Paris: Librairie de Ch. Meyrueis et Compagnie, 1855.

EPPLEY, Daniel F. Richard Hooker (1554-1600). In: LINDBERG, Carter. The Reformation Theologians: An Introduction to Theology in the Early Modern Period. Oxford; Malden: Blackwell, 2002. p. 253-266.

GASSMANN, Günther. Os textos. In: HENDRIX, Scott; GASSMANN, Günther. As Confissões Luteranas: Introdução. São Leopoldo: EST / Sinodal, 2002. p. 38-50.

GIBBS, Lee W. Richard Hooker's Via Media Doctrine of Justification. Harvard Theological Review, v. 74, n. 2, abr. 1981, p. 211-220.

GUGLIERMETTO, Gianluigi. Il pensiero di Richard Hooker all'origine della teologia anglicana. Protestantesimo, v. 69, 2014, p. 351-384.

HOOKER, Richard. A Learned Discourse of Justification, Works, and how the Foundation of Faith is Overthrown. In: The Works of Mr. Richard Hooker. Arranged by The Rev. John Keble. v. 3. Oxford: Clarendon Press, 1884.

. A Preface To Them That Seek (As They Term It) The Reformation [...] In: The Works of Mr. Richard Hooker with a [...]. V. 1. London: J. F. Dove, 1825.

KOLB, Robert. Martin Luther and the Enduring Word of God: The Wittenberg School and Its Scripture-Centered Proclamation. Grand Rapids: Baker Academic, 2016.

LECLER, Joseph. Toleration and the Reformation. v. 2. Translated by T. L. Westow. New York: Association Press; London: Longmans, 1960.

LIVRO DE CONCÓRDIA. 5.ed. São Leopoldo: Sinodal; Canoas: Ulbra; Porto Alegre: Concórdia, 2006.

LUTERO, Martim. Sermons on the Gospel of St. John. In: Luther's Works. v. 22. Edited by Jaroslav Pelikan. CPH: Saint Louis, 1957.

. Preface to the Epistles of St. James and St. Jude. In: Luther's Works. v. 35. Word and

Sacrament I. Edited by E. Theodore Bachmann. Philadelphia: Fortress Press, 1960.

PELIKAN, Jaroslav. The Christian Tradition: A History of the Development of Doctrine. v. 4: Reformation of Church and Dogma (1300-1700). Chicago: The University of Chicago Press, 1985.

WALKER, W. et al. História da Igreja Cristã. São Paulo: ASTE, 2008.

WALTON, Isaac. The Life of Mr. Richard Hooker. In: The Works of Mr. Richard Hooker with $a$ [...]. V. 1. London: J. F. Dove, 1825. 